\title{
Ceftriaxone in the treatment of chronic donovanosis in central Australia
}

\author{
Angela Merianos`, Marisa Gilles, John Chuah`
}

\begin{abstract}
Objectives-To determine the effectiveness of intramuscular (IM) ceftriaxone sodium in the treatment of chronic donovanosis, and the acceptability to patients and staff of supervised outpatient treatment in rural clinics.

Methods-We collected demographic and sexual health data from participants using a standard questionnaire, and recorded their donovanosis lesions at baseline using genital diagrams. Treatment consisted of a single daily IM injection of $1 \mathrm{~g}$ ceftriaxone diluted in $2 \mathrm{ml}$ of $1 \%$ lignocaine. Clinic staff followed patients for between three and 12 months, enabling the detection of late recurrences.
\end{abstract}

Setting-Rural Aboriginal communities in central Australia.

Participants-The study describes eight women and four men with chronic donovanosis in detail, and summarises the outcome in 12 additional cases. All cases presented with advanced lesions which had failed to heal on the standard oral antibiotic regimens used in the region.

Results-The mean duration of infection was 3.0 years (SD 1.9 years), and between four and ten courses of antibiotics had been prescribed for six of the 12 patients. Patients received between 7-26g of ceftriaxone sodium. Clinical improvement was dramatic in most lesions, and four patients healed completely without recurrence after a total $7-10 \mathrm{~g}$ of ceftriaxone. Mild recurrences responded to further ceftriaxone or short courses of oral antibiotics. Treatment was well tolerated, and both patient and staff compliance high.

Conclusion-Donovanosis is an important cause of chronic genital ulceration in central Australia, and is potentially an important risk factor for HIV transmission in Aboriginal communities. The pharmacokinetics and safety profile of ceftriaxone make it a useful and costeffective agent in the ambulatory management of donovanosis, especially in remote communities. Supervised multidrug regimens of two or more longacting agents may provide the best answer in donovanosis, administered through the existing health care infrastructure.

(Genitourin Med 1994;70:84-89)

\section{Introduction}

Donovanosis (granuloma inguinale) is a granulomatous genital infection caused by the intracellular gram negative bacillus Calymmatobacterium granulomatis. It is endemic in Aboriginal people in central Australia who often delay contact with health services until their lesions become painful and malodorous, or they experience loss of sexual function due to destruction of genital tissues, scarring and deformity. ${ }^{1}$ Donovanosis often presents a treatment challenge. Empirical treatment with broad spectrum antibiotics has met with variable success, ${ }^{2-12}$ and in vitro antibiotic sensitivity testing is unavailable. ${ }^{13}$ The risk of serious side effects and impractical dosage schedules proscribes the use of some agents. ${ }^{4} 5$ The advanced lesions frequently seen in central Australia respond poorly to conventional treatment regimens. The antibiotics selected as first line standard treatment in the region, doxycycline and erythromycin, are a compromise between proven efficacy in donovanosis and safety when self-administered. ${ }^{14}$ Compliance with treatment is also problematic. The need for prolonged antibiotic administration is an important cause of treatment failure in chronic donovanosis, which, in our experience, has led to patient and community dissatisfaction with existing treatment protocols. Hospital admission for supervised treatment has resulted in cures, but is socially disruptive and costly, and many patients discharge themselves before healing is complete.

Ceftriaxone sodium ("Rocephin", Roche Products Pty Ltd) has proven efficacy in the treatment of gonorrhoea, ${ }^{15} 16$ syphilis $^{1517} 18$ and chancroid, ${ }^{15}$ and is safe in pregnancy ${ }^{16}$ and breast feeding. ${ }^{19}$ In 1990, we successfully treated two Aboriginal adults with long-standing donovanosis with intramuscular ceftriaxone at a dose of $2 \mathrm{~g}$ daily for 10 consecutive days. All lesions healed without relapse. Treatment was well tolerated, with pain at the injection site the only reported side effect. Both patients completed the course of injections without defaulting. Significant improvement was evident within seven days of treatment, and healing continued after cessation of ceftriaxone leaving depigmented scar tissue. Both patients had previously received multiple courses of doxycycline over several years but admitted to poor compliance. The more severely affected patient had also received a supervised course of chloramphenicol; on examination there was complete erosion of the glans penis and disabling scrotal lymphoedema.

\author{
Address correspondence to: \\ Angela Merianos \\ Accepted for publication \\ 30 November 1993 \\ Australia \\ ^ Formally NT \\ Department of Health \\ and Community
}


In response to these observations, we offered ceftriaxone treatment to 24 patients with donovanosis whose lesions had failed to heal with standard therapy. We describe the physical examination, treatment regimens, compliance, clinical course and treatment side effects of 12 patients for whom we have complete records. All but one were followed for a minimum of three months. We also provide the available details on the remaining 12 patients.

\section{Subjects and methods}

The aims of the investigation were to determine the effectiveness of intramuscular ceftriaxone in the treatment of snip biopsyconfirmed donovanosis that had failed to heal on standard antibiotic regimens recommended for donovanosis. We also wished to confirm the acceptability of outpatient administration of ceftriaxone in rural clinics. We incorporated this study into the normal health care delivery services in central Australia, involving District Medical Officers, Nurses and Aboriginal Health Workers.

We obtained informed written or verbal consent in the presence of an interpreter. Our exclusion criteria were: antibiotic treatment within one month of initial assessment; known allergy to the cephalosporins, penicillins or lignocaine; known haematological, renal or hepatic disease, or immunodeficiency. We also excluded women in the first trimester of pregnancy. Failure of lesions to heal in the past because of non-compliance rather than antibiotic failure was not an indication for exclusion. We defined default from treatment as three consecutive missed doses. Defaulting patients were restarted on ceftriaxone at the discretion of the attending medical officer.

\section{Interviews and physical examination}

We completed a standard questionnaire on each participant, collecting demographic data, details of donovanosis chronicity, previous treatment regimens and hospital admission for donovanosis, compliance on previous antibiotic regimens, and recent syphilis serology results.

Medical officers conducted the pretreatment examination whenever possible, with the nurse responsible for follow-up examinations in attendance. Lesions were measured, and their site and appearance recorded on a standard genital diagram. Examiners also recorded the presence of regional lymphadenopathy, hepatomegaly, and extra-genital donovanosis. A snip biopsy for the demonstration of characteristic intracellular Donovan bodies was taken from the leading edge of a typical lesion after application of local anaesthetic (2-5\% lignocaine jelly), and sent to the regional hospital for microscopy and histological examination. ${ }^{20}$ Subjects refusing biopsy were still eligible for ceftriaxone if documentation of biopsyconfirmed donovanosis diagnosed within 2 years of inclusion into this study was sighted, or the attending medical officer was confident of the clinical diagnosis and active syphilis was excluded serologically. ${ }^{21}{ }^{22}$ Eight of the 12 patients had laboratory confirmed donovanosis. The remaining four were diagnosed clinically. Clinic staff collected blood for syphilis serology, routine haematology, urea and creatinine levels and liver function tests, and performed urinalysis for glucosuria using "Multistix" (Ames Division, Miles Australia Pty Ltd). They also performed urinary pregnancy tests in sexually active women.

Case review was scheduled for day 7 of treatment when neutrophil count and biochemistry were repeated, and at 4, 12 and 26

Table Characteristics of the twelve patients with long standing donovanosis treated with ceftriaxone (CFTX)

\begin{tabular}{|c|c|c|c|c|c|c|c|c|}
\hline $\begin{array}{l}\text { Case } \\
\text { No }\end{array}$ & $\begin{array}{l}\text { Age } \\
\text { (years) }\end{array}$ & Sex & $\begin{array}{l}\text { Years } \\
\text { infected }\end{array}$ & $\begin{array}{l}\text { Number of } \\
\text { previous } \\
\text { antibiotic } \\
\text { courses }\end{array}$ & $\begin{array}{l}\text { Previous } \\
\text { treatment } \\
\text { regimens }\end{array}$ & $\begin{array}{l}\text { Previous } \\
\text { inpatient } \\
\text { treatment }\end{array}$ & $\begin{array}{l}\text { Doses of } \\
\text { CFTX }\end{array}$ & $\begin{array}{l}\text { Healing } \\
\text { occurred }\end{array}$ \\
\hline 1 & 35 & $\mathrm{~F}$ & 4 & 1 & Tetracycline & yes ${ }^{\star}$ & 20 & yes \\
\hline 2 & 20 & $\mathbf{M}$ & 1.5 & 3 & $\begin{array}{l}\text { TMP/SMX } \\
\text { Doxycycline }\end{array}$ & no & 7 & yes \\
\hline 3 & 42 & F & 1 & 7 & $\begin{array}{l}\text { TMP/SMX } \\
\text { Doxycycline }\end{array}$ & no & 18 & yest \\
\hline 4 & 25 & $\mathrm{~F}$ & 6 & $\geqslant 3$ & $\begin{array}{l}\text { TMP/SMX } \\
\text { Doxycycline } \\
\text { Erythromycin }\end{array}$ & no & 18 & yest \\
\hline 5 & 29 & $\mathbf{F}$ & 2 & 4 & $\begin{array}{l}\text { Doxycycline } \\
\text { Erythromycin }\end{array}$ & no & 7 & yest \\
\hline 6 & 38 & $\mathbf{F}$ & 4 & 10 & $\mathrm{TMP} / \mathrm{SMX}$ & no & 26 & yest \\
\hline 7 & 45 & $\mathbf{F}$ & 1 & 10 & $\begin{array}{l}\text { TMP/SMX } \\
\text { Doxycycline } \\
\text { Tetracycline }\end{array}$ & no & 7 & yes \\
\hline 8 & 22 & $\mathbf{F}$ & 2 & 1 & Erythromycin & $14 d$ & 18 & yest \\
\hline 9 & 24 & $\mathbf{F}$ & $2 \cdot 5$ & 1 & Doxycycline & no & 21 & yes \\
\hline 10 & 33 & $\mathbf{M}$ & 3 & 6 & Doxycycline & no & 10 & yes \\
\hline 11 & 22 & $\mathbf{M}$ & 7 & 8 & $\begin{array}{l}\text { Doxycycline } \\
\text { Erythromycin } \\
\text { Ceftriaxone }\end{array}$ & no & 9 & yes \\
\hline 12 & 52 & $\mathbf{M}$ & $2-3$ & 1 & Doxycycline & no & 10 & yes \\
\hline
\end{tabular}

«The reason for admission was left ventricular failure. Treatment of donovanosis was incidental.

tInitial healing was followed by one or more recurrences.

$\$$ This patient received 3-4 doses of ceftriaxone with doxycycline seven months before the course described in this table. He was a known substance abuser (petrol sniffer) before treatment. Positive behavioural change was reported in association with healing of his genital ulceration. 
weeks post-treatment. The observation periods referred to in the table start on the first day of treatment with ceftriaxone sodium. Clinic staff instructed participants to present immediately if lesions recurred. The same schedule was followed to assess progress after treatment of recurrences.

\section{Dosage and administration of ceftriaxone}

Most patients received a primary course of $1 \mathrm{~g}$ ceftriaxone sodium diluted in $2 \mathrm{ml}$ of $1 \%$ lignocaine as a single daily intramuscular injection for 10 days, continued at the discretion of the attending medical officer. Two patients requested intravenous therapy which was delivered via butterfly cannulae re-sited daily. Patient 1 received $2 \mathrm{~g}$ of intramuscular ceftriaxone daily as an outpatient at the regional hospital. She completed the total course of $20 \mathrm{~g}$ before we decided to reduce dosage to $1 \mathrm{~g}$ per day for all new patients admitted to the study. All unbiopsied patients who failed to respond to $14 \mathrm{~g}$ of ceftriaxone were counselled by their doctor about the need for biopsy.

\section{Results}

The figure shows the area of endemicity in central Australia. The table summarises the demographic and clinical characteristics of the 12 patients and previous treatment regimens. The youngest subject was 20 years old and the oldest approximately 52 years (mean SD = $32.3,10 \cdot 4$ years). The average duration of infection was 3.0 years, SD 1.9 years (range 1-7 years). None of the patients had signs of extragenital donovanosis. Six patients had serological evidence of past syphilis; all had been adequately treated and there was no evidence of recent re-infection. One of the clinically diagnosed patients received treatment with benzathine penicillin for concurrent active syphilis (RPR 1:128) which had no effect on the appearance of his penile lesions, thereby strengthening the diagnosis of donovanosis.

Physical examination and clinical course

Case 1 This 35 year old woman presented with an extensive and painful perianal lesion.

Figure The region of central Australia involved in the ceftriaxone study

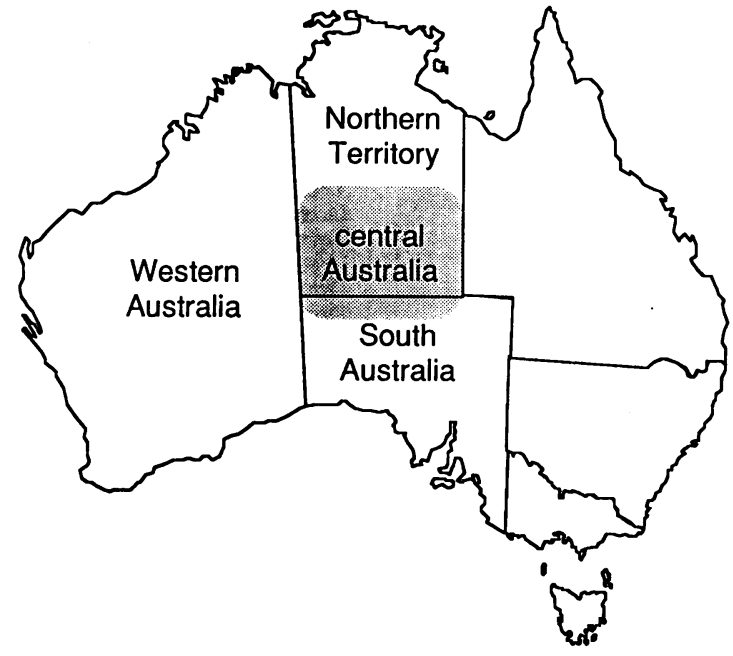

By day 4 of treatment, the lesion was smaller and less friable. Healthy painless granulation tissue had formed by day 7 . She experienced no recurrences.

Case 2 This 20 year old man presented with 2 perianal lesions involving an area of $17 \mathrm{~cm}$ $\times 17 \mathrm{~cm}$. The lesions had healed by day 100 leaving depigmented scar tissue. The skin was? described as normal 30 days after startinge treatment. He has remained disease free.

Case 3 This 42 year old woman presented with a single $12 \mathrm{~cm} \times 8 \mathrm{~cm}$ vulval lesion which involuted to a residual non-ulcerated lesion on the introitus by day 7. She presented with a recurrence in the scar tissue 4 months? after apparent healing, and was treated with a흘 second course of ceftriaxone. Resolution wast again rapid on this occasion, but she represented with a $0.5 \mathrm{~cm} \times 1 \mathrm{~cm}$ vulval lesion $4^{\infty}$ months later. She was then treated with doxycycline $200 \mathrm{mg}$ twice daily for 7 days. She was completely well 6 months later.

Case 4 This 25 year old woman presented? with a single $30 \mathrm{~cm} \times 20 \mathrm{~cm}$ vulval lesiono which decreased in size to $20 \mathrm{~cm} \times 2 \mathrm{~cm}$ and was non-ulcerated by day 7 of treatment. $\oplus$ Depigmented scar tissue was found at the $4 \circ$ week follow-up examination. She presentedwith a small vulval lesion on scar tissue $2 \frac{1}{2}$ months later, received a further $10 \mathrm{~g}$ of ceftriaxone and was well when examined approxi- 8 mately 3 months later. She had a further two ${ }^{+}$ small recurrences during pregnancy and one post-partum. She was given short courses of erythromycin on each occasion and had a nor-o mal vaginal delivery.

Case 5 This 29 year old woman presented $\stackrel{\mathbb{}}{\circ}$ with a single $3 \mathrm{~cm} \times 3 \mathrm{~cm}$ perivulval lesion. $\overrightarrow{\overrightarrow{0}}$ The lesion had healed completely by day 7,3 the last day of treatment. She experienced a minor recurrence on the perineum 9.5 months after ceftriaxone. She was successfully? treated with a short course of erythromycin.

Case 6 This 38 year old woman presentedi with a single $6 \mathrm{~cm} \times 4 \mathrm{~cm}$ vulval lesion, 3 which healed to painless granulation tissue byo day 7 of a 10 day course of ceftriaxone. The lesion had broken down at the 4 week review, and a further $6 \mathrm{~g}$ of ceftriaxone was administered. New lesions were found 5 months later and she was treated with co-trimoxazole. Sheo received a further $10 \mathrm{~g}$ of ceftriaxone for two recurrences over the next 5 months (totak $26 \mathrm{~g}$ ). She has remained disease free after the? last course of treatment.

Case 7 This 45 year old woman presented with a $4 \mathrm{~cm} \times 3 \mathrm{~cm}$ perineal lesion and bilat-o eral vulval oedema. The lesion had virtually healed by day 14 , and she was completely well when reviewed 5 months later. She haso remained well.

Case 8 This 22 year old woman presentedo with extensive involvement of the externatō genitalia, perineum and vagina. Her lesions? showed little improvement after $11 \mathrm{~g}$ of ceftriaxone. The attending medical officer ordered a further 7 days of treatment 2 weeks later. She was well when reviewed 3 months later, and had delivered a healthy infant by normal vaginal delivery. 
Case 9 This 24 year old woman presented with extensive lesions on the introitus, vulva, perineum and perianal area. The vulval and perineal lesions healed by day 7 of treatment and she was completely well at the 3 month review. She had a small recurrence when examined 8 months later and received another $9 \mathrm{~g}$ of ceftriaxone. She was lost to follow-up after the second course.

Case 10 This 33 year old man presented with confluent beefy lesions around the penis, measuring 8-10 sq $\mathrm{cm}$. The granulomas were replaced by painless granulation tissue by day 7 of treatment, and healed completely by day 10 . He was well at the 1 month review.

Case 11 This 22 year old man presented with six friable lesions on the penis and scrotum measuring a total $33 \mathrm{sq} \mathrm{cm}$. Healthy granulation tissue was present by day 7 of treatment, and partial healing was reported by day 28. All lesions had healed completely at the 3 month review, and there were no recurrences more than one year later.

Case 12 This 52 year old man presented with multiple smelly granulomas along the shaft of the penis which were replaced by painless granulation tissue by day 7 of treatment. All lesions had healed completely at the 3 month review and he has remained well.

A mean of $14 \mathrm{~g}$ of ceftriaxone was administered to each patient, with a range of 7 to 26 grams. Three patients required only seven days of treatment; two remained disease free without further intervention. Three patients were anaemic at the pre-treatment assessment with haemoglobin levels of $6.4,8.3$ and $11.7 \mathrm{~g} / \mathrm{dL}$. Ceftriaxone did not adversely affect any haematological parameter, and Patient 6 experienced a rise in haemoglobin from $6.4 \mathrm{~g} / \mathrm{dL}$ to $10.9 \mathrm{~g} / \mathrm{dL}$ during the observation period. Except for a single report of a transient elevation in serum alkaline phosphatase, all biochemical results during treatment remained within normal limits.

Only three patients reported initial healing of their lesions on previous treatment. All patients gave failure to heal or the long duration of treatment regimens as their reason for non-compliance with oral antibiotics. Patients 3 and 7 had completed therapeutic courses of antibiotics without cure. After 30 days of doxycycline, Patient 3 was prescribed trimethoprim $160 \mathrm{mg} /$ sulphamethoxazole 800 mg (TMP/SMX, co-trimoxazole) three tablets daily, but had to stop treatment within one week due to the appearance of a generalised rash. Patient 7, who was admitted into the study in late March 1991, had completed a full 21 day course of doxycycline $100 \mathrm{mg}$ twice daily in February 1991, and had been prescribed a three month course of co-trimoxazole in October 1990.

Intramuscular ceftriaxone was well tolerated and compliance with the treatment regimen was excellent in all but two patients. The only reported side effects of treatment were mild pain and inflammation at the injection sites, and mild nausea in one patient. Two women subsequently successfully completed their pregnancies, and delivered healthy infants by normal vaginal delivery.

We received details of treatment outcome for the additional 12 patients on whom we have few clinical details. All lesions healed in nine patients after 7-20 g of ceftriaxone (mean, 1SD $=14.0 \mathrm{~g}, 3.4 \mathrm{~g}$ ). Healing was incomplete at the four week review in a patient who had received a total $12 \mathrm{~g}$ of ceftriaxone. A 45 year old man healed on ciprofloxacin after $21 \mathrm{~g}$ of ceftriaxone administered over 15 days, and a 69 year old.man diagnosed on clinical ground showed no response after 14 days of treatment. His attending medical officer was consulted about the need for biopsy to exclude penile carcinoma. ${ }^{23}$ One of the nine patients whose lesions healed initially represented with donovanosis a year later, but may have been re-infected.

\section{Discussion}

Ceftriaxone is a third generation cephalosporin with broad spectrum in vitro activity against aerobic and anaerobic bacteria. ${ }^{24} 25$ The pharmacokinetics of ceftriaxone indicate high systemic bioavailability via the intramuscular route, ${ }^{26}$ high serum protein binding and low total body clearance which result in an extended elimination half-life of 6-10 hours. ${ }^{26}{ }^{27}$ After single $1 \mathrm{~g}$ doses of ceftriaxone, serum concentrations have exceeded the minimal inhibitory concentrations $\left(\mathrm{MlC}_{90}\right)$ of most Enterobacteriaceae for 24 hours. ${ }^{24}{ }^{25}$ As previously shown in paediatric practice, intramuscular ceftriaxone as a once daily injection has an important role in the ambulatory care of patients with severe infections. ${ }^{28}$

In Australia's Northern Territory (NT), most patients with donovanosis are reported from central Australia although the disease is also endemic in the tropical north. Since 1987, an average of 36 new cases are diagnosed annually in the NT; a crude incidence of 1 per 1000 Aboriginal people per year. Donovanosis is a notiflable disease in the Northern Territory, and our surveillance data suggest that the incidence of disease varies considerably between communities. We do not know whether these data reflect true differences in incidence or regional differences in the utilisation of health services and reporting practices of medical officers. An informal survey in the catchment communities of one central Australian rural health clinic detected a minimum prevalence of 11.7 per 1000 (17/1456), indicating that failure to present for examination and under-reporting by health professionals has led to significant underestimation of the true prevalence.

The successful treatment of donovanosis is dependent on patient compliance, and the commitment of health care providers to encourage defaulting patients and monitor progress over time. In central Australia, poor compliance with self-administrated oral antibiotics has resulted in a cycle of low cure rates, relapse, chronic disease, the need for 
long and impractical treatment regimens, and delays in presentation for treatment among new and relapsing cases based on the belief that treatment is futile. Anecdotal evidence from health care providers in the region suggests that multiply resistant organisms may be important in compliant patients with relapsing disease. Poor compliance may also be influenced by patients' perception that parenteral antibiotics are more efficacious than oral preparations. ${ }^{29}$ Given the limitations of standard treatment in our patients, the aims of this study were to determine the efficacy of a parenteral agent in chronic donovanosis, and the feasibility of supervised treatment within a remote area health service infrastructure.

Compliance with the ceftriaxone regimen was very high, especially once clinical improvement was visible to patients. Pain at the injection site was minimised by the use of a small volume of lignocaine for resuspension $(2 \mathrm{ml}$ rather than the recommended $3.5 \mathrm{ml}$ for $1 \mathrm{~g}$ of ceftriaxone) without precipitation of the drug. ${ }^{28}$ Only one patient missed three consecutive doses during the first course of treatment. A second patient missed doses during her second course. Only four of our 12 patients with well documented histories healed without recurrence after one course of 7-10 $\mathrm{g}$ of ceftriaxone, but all patients exhibited marked improvement after approximately seven days of treatment. The characteristic beefy granulomas which bled on contact were replaced by healthy granulation tissue, and the characteristic smell of secondary bacterial infection disappeared. ${ }^{23}$

Relapse in donovanosis is relatively frequent and may occur 6-18 months after re-epithelialisation. ${ }^{20}$ Conversely, full healing may occur in some lesions even if antibiotics are stopped before re-epithelialisation is complete, but the recurrence rate is higher. ${ }^{20}$ Localised recurrences in this study were successfully treated with short courses of ceftriaxone or oral antibiotics.

The psychosexual trauma of chronic donovanosis cannot be over-emphasised. People with long standing disease are often socially isolated because of the smell, and extensive genital destruction leaves them unacceptable as sexual partners. This case series represents highly motivated self-selected patients, and referred patients who received considerable counselling before inclusion into the study, but health workers reported that all patients were very satisfied with their rapid improvement and believed in the efficacy of the treatment. All stated that the quality of their lives had improved significantly, even after recurrences.

The disproportionate number of female patients in this series reflects the greater availability of female health professionals in central Australia. Cultural taboos against genital examination of men by female clinic staff may result in inadequate patient ascertainment among Aboriginal men. Detection of sexually transmitted diseases in women is also facilitated by the intensity of antenatal screening in the region. Donovanosis is not thought to be easily transmitted from person to person, even between regular sexual partners, but failure to examine and treat male partners has serious implications for control of all sexually transmitted diseases (STD) in Aboriginal communities. ${ }^{23}$ As genital examination of male partners was seldom possible, some of the late "recurrences" in this series may have followed re-infection from an untreated source.

Indigenous transmission of HIV has yet to be reported in central Australia, but a locally acquired HIV infection was detected in an Aboriginal man in Darwin in $1993 .{ }^{30}$ Aboriginal communities are exposed to many of the risk factors which facilitate heterosexual transmission of HIV in Africa. ${ }^{31} 32$ Important risk factors and behaviours include high rates of STD, substance abuse and population mobility. Traditional scarification is also practiced in some communities. The association between HIV and ulcerative genital disease is well recognised. ${ }^{32-34}$ In Nairobi, Cameron et al found that male STD clinic clients presenting with acute genital ulcer disease after prostitute contact had 4.7 times the risk of seroconversion to HIV than men without genital ulceration, after adjustment for the frequency of contact with prostitutes and circumcision. ${ }^{34}$ After a single exposure to an HIV-infected woman, the crude cumulative HIV seroconversion rate over a 71 week observation period was $3 \%$. The cumulative estimate after a single exposure was a minimum of $43 \%$ in uncircumcised men with genital ulcer disease, and there is evidence that male to female transmission is even more efficient. ${ }^{32}$ HIV has been isolated from the surface of genital ulcers by viral culture and detected by polymerase chain reaction. ${ }^{35} 36$

In spite of the favourable observations of this case series, our study has several limitations. First, we are unable to determine how many inadequately documented patients were started on ceftriaxone, so we may be over-estimating the effect of this agent. This is a recurring difficulty in the provision of medical care to highly mobile populations with health and life style priorities outside the Western medical model. Second, the intrinsic efficacy of ceftriaxone in donovanosis is confounded by the effect of supervised treatment with follow-up under study conditions. Several studies have shown higher cure rates with co-trimoxazole ${ }^{10}{ }^{11}$ and norfloxacin, ${ }^{11}$ which are convenient alternatives to parenteral administration. However, these series are not directly comparable with our study population in terms of disease chronicity and observation period. Ramanan and co-workers, for example, successfully treated 10 patients with norfloxacin, but the average duration of disease was 19 days and follow-up was only for one month. ${ }^{11}$ The average duration of infection in our patients was three years, suggesting significant local dissemination of the pathogen and general tissue necrosis. We were also able to monitor clinical progress for at least three months in all but one patient, so 
our ability to detect late relapses may have lowered the apparent cure rate.

Ceftriaxone sodium is not a "magic bullet", but is currently a useful alternative to the oral antibiotic armamentarium for donovanosis. Its long elimination half-life, high systemic bioavailability and steady state characteristics give it a theoretical advantage over short acting agents in extensive disease. ${ }^{26}{ }^{27}$ Ceftriaxone appears effective in quickly reducing the bulk of infected tissue, thereby enabling the successful treatment of residual disease or localised recurrences with oral antibiotics. Multidrug therapy with two or more longacting agents may provide the regimen of choice in donovanosis. By integrating the study into the existing rural health care delivery system the cost of treatment and disruption of patients' lives by admission to hospital were kept to a minimum. The cost of this treatment regimen was much less than inpatient treatment in our setting. Limited health budgets may prohibit its widespread use in developing countries. Single dose treatment of donovanosis with $250-500 \mathrm{mg}$ of ceftriaxone proved ineffective in curing disease in a study in Durban. ${ }^{37}$

Controlled clinical trials comparing ceftriaxone to existing treatment regimens are necessary before ceftriaxone is considered standard therapy in donovanosis. Some of the considerations of a suitable agent in our setting include once daily administration, safety in pregnancy, a rapid clinical response and minimal supervision within the existing health infrastructure.

We thank Dr Bart Currie in Darwin for his input into planning the study, Mr Michael Halstead, Medical Manager of Roche the study, Mr Michael Halstead, Medical Manager of Roche Products Pty Ltd for his comments and Mr Brian Caught of
Roche for his support. Our patient series would not have been Roche for his support. Our patient series would not have been
possible without the collaboration of the medical officers, rural possible without the collaboration of the medical officers, rural
nurses and Aboriginal Health Workers of the Northern nurses and Aboriginal Health Workers of the Northern Nganampa Health Council of the Pitjantjatjara Homelands South Australia and the Central Australian Aborigina Congress in Alice Springs, who provided the clinical details, supervised ceftriaxone treatment and reviewed patients. We also thank the Aboriginal communities who supported ou investigation, the Aboriginal Management of the Central Australian Aboriginal Congress, and the Central Australian Rural Practitioners Association.

1 Kuberski T. Granuloma inguinale (Donovanosis). Sex Transm Dis 1980;7:29-36.

2 Ghosh S, Ghosh R. Donovanosis treated with erythromycin parenterally. Report of the first case. $B r \mathcal{F}$ Venereal Dis 1959;35:260-1.

3 Ashdown LR, Kilvert GT. Granuloma inguinale in northern Queensland. Med $\mathcal{f}$ Aust 1979;1:146-8.

4 Francke EL, Neu HC. Chloramphenicol and tetracyclines. Medical Clinics of North America 1987;71:1155-68.

5 Robinson RCV, Wells TL. Intramuscular chloramphenico in the treatment of gonorrhoea and granuloma inguinale. American fournal of Syphilis 1952;36:264-8.

6 O'Farrell N. Failure of single dose spectinomycin in granuloma inguinale (donovanosis). Trans $R$ Soc Trop Med Hyg 1990;84:862.

7 Sengupta SK, Das N. Donovanosis affecting cervix uterus, and adnexae. Am $\mathcal{F}$ Trop Med Hyg 1984;33: $632-6$.
8 Jerath VP, Jerath R. Donovanosis: unusual therapy. Indian f Sex Transm Dis 1985;6:21-22.

9 Coovadia YM, Steinberg JL, Kharsany A. Granuloma inguinale (donovanosis) of the oral cavity. $S$ Afr Med $\mathcal{J}$ 1985;68:815-7.

10 Latif AS, Mason PR, Paraiwa E. The treatment of donovanosis (granuloma inguinale). Sex Transm Dis 1988 15:27-9.

11 Garg BR, Lal S, Sivamani S. Efficacy of co-trimoxazole in donovanosis. A preliminary report. $\mathrm{Br} \mathcal{F}$ Venereal Dis 1978;54:348-9.

12 Ramanan C, Sarma PSA, Ghorpade A, Das M. Treatment of donovanosis with norfloxacin. Int $f$ Dermatol 1990; 29:298-9.

13 Sehgal VN, Prasad AL. Donovanosis-Current concepts. Int $\mathcal{F}$ Dermatol 1986;5:8-16.

14 Central Australian Rural Practitioners Association. CARPA Standard Treatment Manual. 1st Ed. Alice Springs: 1992

15 Le Saux N, Ronald AR. Role of ceftriaxone in sexually transmitted diseases. Rev Infect Dis 1989;11:299-308.

16 Cavenee MR, Farris JR, Spalding TR, Barnes DL Castaneda YS, Wendel GD. Treatment of gonorrhoea in pregnancy. Obstet Gynecol 1993;81:33-8.

17 Hook EW, Roddy RE, Handsfield HH. Ceftriaxone therapy for incubating and early syphilis. $\mathcal{f}$ Infect Dis 1988; 158:881-4.

18 Schöfer H, Vogt HJ, Milbradt R. Ceftriaxone for the treatment of primary and secondary syphilis. Chemotherapy 1989;35:140-5.

19 Kafetzis DA, Brater DC, Fanourgakis JE, Voyatzis J, Georgakopoulos P. Ceftriaxone distribution between maternal blood and fetal blood and tissues at parturition maternal blood and fetal blood and tissues at parturition and between blood and milk pos

20 Richens J. The diagnosis and treatment of donovanosis (granuloma inguinale). Genitourin Med 1991;67 441-52.

21 Cameron DW, Padian NS. Sexual transmission of donovanosis (granuloma inguinale). Genitourin Med 1991;67: 441-52.

22 Sackett DL, Holland WW. Controversy in the detection of disease. Lancet 1975;ii:357-9.

23 Hart G. Donovanosis. In: Holmes KK, Mårdh PA, Sparling PF, Wiesner PJ, eds. Sexually transmitted disSparling PF, Wiesner PJ, eds. Sexually transmith

24 Brogden RN, Ward A. Ceftriaxone: A reappraisal of its antibacterial activity and pharmacokinetic properties, and an update on its therapeutic use with particula reference to once-daily administration. Drugs 1988;35 $604-45$.

25 Scully BE, Fu KP, Neu HC. Pharmacokinetics of ceftriaxone after intravenous and intramuscular injection. $\mathrm{Am}$ Med 1984;77:112-6.

26 Bergen T. Pharmacokinetics and tissue penetration of ceftriaxone. Insights into the treatment of serious infection 1988;2:15-29.

27 Mazzei T, Periti P. Tissue distribution of antimicrobial drugs. F Chemother 1989;1:175-9.

28 Bradley JS, Compogiannis LS, Murray WE, Acosta MA Tsu GL. Pharmacokinetics and safety of intramuscular injection of concentrated ceftriaxone in children. Clin injection of concentrated

29 O'Farrell N. HIV, genital ulceration, and granuloma inguinale. BMF 1988;296:935.

30 Bowden F, Patel A. Locally acquired HIV infection in Northern Territory Aborigine. Comm Dis Intell 1993; 17:307.

31 Piot $\mathrm{P}$, Laga $M$, Ryder $R$, et al. The global epidemiology of HIV infection: continuity, heterogeneity, and change. F Acquir Immune Defici Syndr 1990;3:403-12.

32 Plummer FA, Cameron DW, Simonsen JN, et al. Cofactors in male-female transmission of HIV. $\mathcal{F}$ Infect Dis 1991;163:233-9.

33 Mertens TE, Hayes RI, Smith PG. Epidemiologic methods to study the interaction between HIV infection and other sexually transmitted diseases. AIDS 1990;4: and oth

34 Cameron DW, Simonsen JN, D'Costa LJ et al. Female to male transmission of human immunodeficiency virus type 1: risk factors for seroconversion in men. Lance 1989;11:403-7.

35 Kreiss JK, Coombs R, Plummer FA, et al. Isolation of human immunodeficiency virus from genital ulcers in Nairobi prostitutes. $\mathcal{F}$ Infect Dis 1989;160:380-4.

36 Plummer FA, Wainberg MA, Plourde P, et al. Detection of human immunodeficiency virus type 1 (HIV-I) in genital ulcer exudate of HIV-I infected man by culture and gen amplification. F Infect Dis 1990;161:810-1.

37 O'Farrell N. Failure of single dose ceftriaxone in donovanosis (granuloma inguinale). Genitourin Med 1991;67: 269-70. 